\title{
Yearly evolution of organ damage markers in diabetes or metabolic syndrome: data from the LOD-DIABETES study
}

\author{
Manuel A Gomez-Marcos*, Jose I Recio-Rodríguez ${ }^{1}$, Maria C Patino-Alonso², Cristina Agudo-Conde ${ }^{1}$,
} Leticia Gomez-Sanchez', Emiliano Rodriguez-Sanchez¹, Marta Gomez-Sanchez ${ }^{1}$ and Luis Garcia-Ortiz ${ }^{1}$

\begin{abstract}
Background: Cardiovascular disease morbidity-mortality is greater in people with type 2 diabetes mellitus or metabolic syndrome. The purpose of this study was to evaluate the yearly evolution of organ damage markers in diabetes or metabolic syndrome, and to analyze the associated factors.

Methods: An observational prospective study was carried out in the primary care setting, involving 112 patients: 68 diabetics and 44 subjects with metabolic syndrome, subjected to 12 months of follow-up. Measurements: traditional cardiovascular risk factors (blood pressure, blood glucose, lipids, smoking, body mass index (BMI) and) and non-traditional risk factors (waist circumference, hsC Reactive Protein and fibrinogen); subclinical vascular (carotid intima-media thickness, pulse wave velocity and ankle/brachial index), cardiac (Cornell voltage-duration product), renal organ damage (creatinine, glomerular filtration and albumin/creatinine index), and antihypertensive and lipid-lowering drugs.

Results: At baseline, the diabetics presented a mean age of 59.9 years, versus 55.2 years in the subjects with metabolic syndrome $(p=0.03)$. Diastolic blood pressure, total cholesterol and HDL-cholesterol were lower among the patients with diabetes, while blood glucose and $\mathrm{HbA1c}$, as well as antihypertensive and lipid-lowering drug use, were greater. At evaluation after one year, the diabetics showed a decrease in BMI (-0.39), diastolic blood pressure (-3.59), and an increase in fibrinogen $(30.23 \mathrm{mg} / \mathrm{dL})$, ankle/brachial index $(0.07)$ and the number of patients with ankle/brachial index pathologic decreased in 6 . In turn, the patients with metabolic syndrome showed an increase in HDL-cholesterol (1-91 mg/dL), fibrinogen (25.54 mg/dL), Cornell voltage-duration product (184.22 mm/ $\mathrm{ms})$, ankle/brachial index (0.05) and the use of antihypertensive and lipid-lowering drugs, and a reduction in serum glucose $(3.74 \mathrm{mg} / \mathrm{dL}), \mathrm{HOMA}$, systolic $(-6.76 \mathrm{mmHg})$, diastolic blood pressure $(-3.29 \mathrm{mmHg})$, and pulse wave velocity $(-0.72 \mathrm{~m} / \mathrm{s})$. The variable that best predicted a decrease in pulse wave velocity in subjects with metabolic syndrome was seen to be an increase in antihypertensive drug use.
\end{abstract}

Conclusions: The annual assessment of cardiovascular risk factors and the decrease in pulse wave velocity was more favorable in the patients with metabolic syndrome, probably influenced by the increased percentage of subjects treated with antihypertensive and lipid lowering drugs in this group.

Keywords: Subclinical organ damage, Cardiovascular disease, Type 2 diabetes mellitus, Metabolic syndrome

\footnotetext{
* Correspondence: magomez@usal.es

'Primary Care Research Unit, La Alamedilla Health Centre, Salamanca, Spain

Full list of author information is available at the end of the article
} 


\section{Introduction}

Cardiovascular disease morbidity-mortality is greater in people with type 2 diabetes mellitus (T2DM) or metabolic syndrome [1-4]. The presence of target organ damage (TOD) increases the risk of cardiovascular complications independently of the existing estimated risk [5,6]. In this context, left ventricular hypertrophy (LVH), assessed according to electrocardiographic criteria, increases the risk of coronary complications and stroke $[7,8]$. The worsening of renal function, assessed by increased creatinine levels, a drop in glomerular filtration rate (GFR), or an increase in protein excretion in urine, increases the risk of cardiovascular diseases $[9,10]$. Peripheral arterial disease, evaluated by the ankle/brachial index (ABI), is correlated to the development of coronary complications, the incidence of stroke, and cardiovascular mortality [11]. The ultrasound measurement of common carotid artery intima-media thickness (IMTCc) allows the evaluation of vascular structure and the early detection of atherosclerotic lesions, representing a good predictor of future vascular events and a surrogate marker of atherosclerosis [12,13]. IMTCc in T2DM is $0.13 \mathrm{~mm}$ greater than in the controls. This implies an age increment of 10 years, and is associated to a $40 \%$ increase in cardiovascular risk [14]. Likewise, an increase in arterial stiffness, assessed by pulse wave velocity (PWV), predicts future cardiovascular events and mortality of any cause in both hypertensive subjects and in the general population $[15,16]$, though the role played in individuals with Metabolic syndrome $[17,18]$ or T2DM is not clear [19]. Thus, it is important to know the evolution of the different cardiovascular risk factors and of cardiac, renal and vascular TOD, as well as the corresponding conditioning factors in patients with diabetes or metabolic syndrome.

We postulate that the evolution of the different risk factors and target organ damage is similar in both groups, since the antihypertensive drugs, lipid lowering drugs and metformin with beneficial effects upon blood pressure, lipid profile and target organ damage, are used in greater percentages in the group of patients with T2DM.

The purpose of this study was to evaluate the yearly evolution of organ damage markers in diabetes or metabolic syndrome, and to analyze the associated factors.

\section{Materials and methods}

\section{Study design and population}

A prospective observational study was carried out in a primary care setting. Using consecutive sampling, we included 112 patients with type 2 diabetes mellitus $(\mathrm{T} 2 \mathrm{DM})(\mathrm{n}=68)$ (defined using the American Diabetes Association criteria [20]) or metabolic syndrome ( $\mathrm{n}=$ 44)(defined according to the National Cholesterol Education Program, ATP III1 definition [21]) from a population of 46,000 people corresponding to two primary care centers (including 2412 diagnosed with diabetes and 4100 with metabolic syndrome). The study included patients with diabetes or metabolic syndrome who visited their family doctor from January 2009 to January 2010, with none of the following exclusion criteria: patients unable to comply with the protocol requirements (psychological and/or cognitive disorders, failure to cooperate, educational limitations and problems for understanding written language, failure to sign the informed consent document); patients participating or programmed to participate in a clinical trial during the study; and patients with serious comorbidities representing a threat to life over the subsequent 12 months. The sample size was estimated to detect as statistically significant a difference in carotid IMT $\geq 0.05 \mathrm{~mm}$ between baseline and first year evaluation. Accepting an alpha risk of 0.05 and a beta risk of 0.2 in a two-sided test, and assuming a standard deviation of $0.11 \mathrm{~mm}, 40$ subjects were seen to be necessary, assuming a dropout rate of $5 \%$. The study was approved by an independent ethics committee of Salamanca University Hospital (Spain), and all participants gave written informed consent according to the general recommendations of the Declaration of Helsinki [22]. The LOD-DIABETES Study comprises a cohort of 68 diabetics and 44 subjects with metabolic syndrome subjected to annual evaluation of vascular, renal and cardiac target organ damage (TOD).

\section{Measurements}

A detailed description has been published elsewhere of how the clinical data were collected, the anthropometric measurements were made, blood pressure was recorded, TOD was assessed, and the analytical parameters were obtained [23].

\section{Blood pressure}

Office or clinical blood pressure measurement was obtained by performing three measurements of systolic (SBP) and diastolic blood pressure (DBP), using the average of the last two, with a validated OMRON model M7 sphygmomanometer (Omron Health Care, Kyoto, Japan), and following the recommendations of the European Society of Hypertension [24]. The mean of the last two measurements obtained by the nurse of the research unit from the arm with high blood pressure was used for the study.

\section{Vascular assessment}

\section{Assessment of carotid intima-media thickness (IMT)}

Carotid ultrasound to assess IMT was performed by two investigators trained for this purpose before starting the 
study. The reliability of assessment was evaluated before the study, using the intraclass correlation coefficient, which showed values of 0.974 (95\%CI: 0.935 to 0.990 ) for intra-observer agreement on repeated measurements in 20 subjects, and 0.897 (95\%CI: 0.740 to 0.959 ) for inter-observer agreement. According to the Bland-Altman analysis, the limit of inter-observer agreement was 0.022 (95\%CI: -0.053 to 0.098 ), and the limit of intraobserver agreement was 0.012 (95\%CI: -0.034 to 0.059$)$. A Sonosite Micromax ultrasound device paired with a 5-10 MHz multifrequency high-resolution linear transducer with Sonocal software was used for performing automatic measurements of IMT in order to optimize reproducibility. Measurements were made of the common carotid after the examination of a longitudinal section of $10 \mathrm{~mm}$ at a distance of $1 \mathrm{~cm}$ from the bifurcation, performing measurements in the anterior or proximal wall, and in the posterior or distal wall in the lateral, anterior and posterior projections - following an axis perpendicular to the artery to discriminate two lines: one corresponding to the intima-blood interface and the other to the media-adventitious interface. A total of 6 measurements were obtained of the right carotid and another 6 of the left carotid, using average values (average IMT) and maximum values (maximum IMT) calculated automatically by the software. The measurements were obtained with the subject lying down, with the head extended and slightly turned opposite to the exploratory side, following the recommendations of the Manheim Carotid Intima-Media Thickness Consensus [25]. The average IMT was considered abnormal if $>0.90 \mathrm{~mm}$, or if there were atherosclerotic plaques with a diameter $1.5 \mathrm{~mm}$ or a focal increase of $0.5 \mathrm{~mm}$ or $50 \%$ of the adjacent IMT.

\section{Evaluation of peripheral artery involvement}

This was evaluated using the ankle-brachial index (ABI). The pressure in the extremities was measured using a portable Doppler system Minidop Es-100Vx (Hadeco, Inc. Arima, Miyamae-ku, Kawasaki, Japan) applying the probe at the anterior or posterior tibial artery at an angle of approximately $60^{\circ}$ to the direction of blood flow. The ABI was calculated separately for each foot by dividing the greater of the two systolic pressures in the ankle by the greater of the two systolic pressures in the arm. TOD was considered if ABI < 0.9 [24].

\section{Pulse wave velocity (PWV)}

This parameter was estimated using the SphymgoCor System (AtCor Medical Pty Ltd Head Office, West Ryde, Australia), with the patient in the supine position. The pulse waves of the carotid and femoral arteries were analyzed, estimating the delay with respect to the ECG wave and calculating the corresponding PWV. Distance measurements were taken with a measuring tape from the sternal notch to the carotid and femoral arteries at the sensor location. TOD was considered if PWV > $12 \mathrm{~m} / \mathrm{s}$ [24].

\section{Renal assessment}

Kidney damage was assessed by measuring plasma creatinine concentration. Glomerular filtration rate (GFR) was estimated according to the CKD-EPI (Chronic Kidney Disease Epidemiology Collaboration) [26] for Caucasians, and proteinuria was assessed from the albumin/ creatinine ratio following the ESH 2007 criteria. TOD was defined as plasma creatinine $\geq 1.3 \mathrm{mg} / 100 \mathrm{ml}$ in men and $\geq 1.2 \mathrm{mg} / 100 \mathrm{ml}$ in women; GFR $<60 \mathrm{ml} / \mathrm{min}$; or albumin/creatinine ratio $\geq 22 \mathrm{mg} / \mathrm{g}$ in men and $\geq 31$ $\mathrm{mg} / \mathrm{g}$ in women [24].

\section{Cardiac assessment}

The electrocardiographic examination was performed using a General Electric MAC 3.500 ECG System (General Electric, Niskayuna, NY, USA) that automatically measures the voltage and duration of waves and estimates the criteria of the Cornell voltage-duration product (Cornell VDP) [27]. TOD was defined according to the 2007 European Society of Hypertension/European Society of Cardiology guidelines criteria [24].

Information about kilocalorie intake was collected using the food frequency questionnaire of the University of Navarre, validated for Spain [28]. In order to classify patients as active or non-active cases, we considered sedentary patients as those failing to follow the recommendations of the Centers for Disease Control and Prevention: accumulation of at least $30 \mathrm{~min}$ of moderate physical activity 5 or more days a week, or three or more sessions of intense activity a week, each with a minimum duration of $30 \mathrm{~min}$. The individuals performing the different tests were blinded to the clinical data of the patient.

\section{Statistical analysis}

Continuous variables are expressed as the mean \pm standard deviation, and qualitative variables as frequency distributions. To analyze the changes in the different variables between the two assessments, use was made of the Student t-test for paired quantitative data, with application of the McNemar test for qualitative variables. The multivariate analysis involved a stepwise multiple linear regression model, using as dependent variables those resulting from the differences in evaluation of the target organ lesions between the two measures (Difference IMT = IMT2-IMT1, Difference PWV = PWV2-PWV1, Difference PDVCORNELL = PDVCORNELL2- PDVCORNELL1, and Difference ABI $=\mathrm{ABI} 2-\mathrm{ABI} 1)$. After adjusting for age and sex, we included as independent variables in the analysis for each of the two groups those variables obtained from the differences between the two evaluations that reached statistical significance in the diabetes group (BMI, 
fibrinogen and DBP) and in the metabolic syndrome group (HDL-cholesterol, baseline blood glucose, fibrinogen, HOMA, SBP, DBP, antihypertensive drugs and lipid-lowering drugs). In a second step using the stepwise method, only those variables which reached statistical significance in the regression model remained in the result of the analysis. The data were analyzed using the SPSS version 18.0 statistical package (SPSS Inc., Chicago, Illinois, USA). A value of $\mathrm{p}<0.05$ was considered statistically significant.

\section{Results}

Throughout the year of study of follow-up, two males died as a result of acute myocardial infarction, one with T2DM and the other with metabolic syndrome (aged 76 and 65 years, respectively).

At the baseline evaluation, the diabetic patients were 4.5 years older on average $(p=0.03)$, with a greater percentage of past cardiovascular events, higher C-reactive protein, fibrinogen and HOMA values, and less favorable vascular, renal and cardiac damage indicators, presentando un mayor porcentaje de pacientes activos (45.60\% vs $29.50 \%)$. In contrast, the subjects with metabolic syndrome showed a poorer lipid profile, and poorer obesity and blood pressure parameters, though for most of the analyzed variables the differences failed to reach statistical significance. Mean antihypertensive and lipidlowering drug use was greater among the patients with T2DM. La ingesta calórica día fue similar en los dos grupos $(2449.29 \pm 726.42$ vs $2477.08 \pm 849.93)$.

Evaluation after one year, the behavior of the risk factors was similar to that of the data commented above, with a tendency towards improvement of the obesity, lipid profile and blood pressure parameters in both groups. However, IMTCc was seen to equalize in both groups, PWV decreased, and the Cornell voltage-duration product increased in the patients with metabolic syndrome. Antihypertensive and lipid-lowering drug use increased in the subjects with metabolic syndrome (Tables 1, 2, 3 and 4).

On analyzing the differences in the risk factors, vascular, renal and cardiac TOD and antihypertensive and

Table 1 General demographic and clinics characteristics in Diabetics

\begin{tabular}{|c|c|c|c|c|c|c|c|}
\hline Variables & Basal evaluation & Annual review & Differences & IC 95\% & & p Value & \\
\hline Number (\%) & $68(60.70)$ & $67(58.90)$ & & & & & \\
\hline Age (years) & $59.91 \pm 10.08$ & $60.91 \pm 10.08$ & & & & & \\
\hline Males n (\%) & $43(63.20)$ & $42(62.68)$ & & & & & \\
\hline Years of evolution & $5.41 \pm 4.19$ & $6.41 \pm 4.19$ & & & & & \\
\hline Smokers n (\%) & $16(23.50)$ & $16(25.00)$ & & & & & \\
\hline Ischemic heart disease n (\%) & $8(11.80)$ & $8(12.50)$ & & & & & \\
\hline Cerebrovascular disease n (\%) & $2(2.90)$ & $2(2.50)$ & & & & & \\
\hline BMI $\left(k g / m^{2}\right)$ & $30.08 \pm 4.96$ & $29.71 \pm 5.28$ & -0.39 & -0.69 & to & -0.08 & 0.014 \\
\hline Waist circumference (cm) & $102.93 \pm 12.73$ & $101.63 \pm 13.74$ & -1.30 & -2.08 & to & 0.11 & 0.078 \\
\hline Total Cholesterol (mg/dL) & $187.54 \pm 33.97$ & $185.84 \pm 37.10$ & -1.70 & -10.36 & to & 5.43 & 0.534 \\
\hline Tryglicerides (mg/dL) & $143.90 \pm 68.25$ & $141.63 \pm 76.03$ & -2.24 & -14.90 & to & 13.62 & 0.929 \\
\hline LDL cholesterol (mg/dL) & $108.61 \pm 28.45$ & $107.95 \pm 28.91$ & -0.66 & -8.33 & to & 5.28 & 0.656 \\
\hline HDL cholesterol (mg/dL) & $48.61 \pm 11.69$ & $48.48 \pm 12.09$ & -0.13 & -2.06 & to & 1.52 & 0.764 \\
\hline Serum glucose $(\mathrm{mg} / \mathrm{dL})$ & $126.68 \pm 35.34$ & $132.48 \pm 45.81$ & 5.80 & -0.45 & to & 14.54 & 0.065 \\
\hline $\mathrm{HbA} 1 \mathrm{c}(\%)$ & $6.83 \pm 1.17$ & $7.01 \pm 1.33$ & 0.18 & -0.07 & to & 0.41 & 0.159 \\
\hline Serum creatinine, (mg/dL) & $0.86 \pm 0.17$ & $0.86 \pm 0.21$ & 0.00 & -0.04 & to & 0.04 & 1.000 \\
\hline hs-c-reactive (mg/dL) & $0.34 \pm 0.51$ & $0.32 \pm 0.42$ & -0.02 & -0.17 & to & 0.10 & 0.631 \\
\hline Fibrinogen (mg/dL) & $337.16 \pm 61.16$ & $365.82 \pm 93.23$ & 26.66 & 6.18 & to & 54.28 & 0.015 \\
\hline HOMA-IR & $3.24 \pm 2.69$ & $3.34 \pm 3.82$ & 1.00 & -0.38 & to & 1.24 & 0.287 \\
\hline Office SBP (mm Hg) & $136.13 \pm 19.09$ & $132.44 \pm 18.80$ & -3.69 & -8.16 & to & 1.16 & 0.139 \\
\hline Office DBP (mm Hg) & $82.64 \pm 11.59$ & $78.92 \pm 9.82$ & -3.72 & -6.08 & to & -1.10 & 0.005 \\
\hline Office PP, mm Hg & $53.88 \pm 14.38$ & $54.69 \pm 17.64$ & 0.81 & -2.65 & to & 4.27 & 0.640 \\
\hline Office HR & $72.10 \pm 12.43$ & $70.56 \pm 11.06$ & -1.54 & -2.81 & to & 1.36 & 0.488 \\
\hline Mean Antihypertensive Drugs & $1.51 \pm 1.15$ & $1.57 \pm 1.21$ & 0.06 & -0.17 & to & 0.28 & 0.603 \\
\hline Antihypertensive Drugs, n (\%) & $52(76.50)$ & $51(75.00)$ & -1.5 & -1.4 & to & 1.5 & 0.625 \\
\hline Mean Lipid lowering drugs & $0.68 \pm 0.56$ & $0.66 \pm 0.56$ & -0.01 & -0.10 & to & 0.07 & 0.742 \\
\hline Lipid lowering drugs, n (\%) & $45(66.20)$ & $44(64.70)$ & -1.5 & -1.8 & to & 1.6 & 0.687 \\
\hline
\end{tabular}

Data for qualitative variables are expressed as $\mathrm{N}$ : number (\%) and quantitative variables as mean \pm standard deviation. BMI: body mass index; LDL: low density lipoprotein; HDL: high density lipoprotein; HbA1C: glycosylated hemoglobin; HOMA-IR: homeostasis model assessment insulin resistance; SBP: Systolic blood pressure; DBP: Diastolic blood pressure; PP: pulse pressure; HR: heart rate. 
Table 2 General demographic and clinics characteristics in Metabolic Syndrome

\begin{tabular}{|c|c|c|c|c|c|c|c|}
\hline Variables & Basal evaluation & Annual review & Differences & IC $95 \%$ & & $\mathrm{p}$ Value & \\
\hline Number (\%) & 44 & 43 & & & & & \\
\hline Age (years) & $55.20 \pm 12.49$ & $56.20 \pm 12.49$ & & & & & \\
\hline Males n (\%) & $28(63.60)$ & $27(62.79)$ & & & & & \\
\hline Years of evolution & $1.58 \pm 2.06$ & $1.58 \pm 2.06$ & & & & & \\
\hline Smokers n (\%) & $9(20.50)$ & $9(20.93)$ & & & & & \\
\hline Ischemic heart disease n (\%) & $2(4.50)$ & $2(4.65)$ & & & & & \\
\hline Cerebrovascular disease n (\%) & $0(0.00)$ & $0(0.00)$ & & & & & \\
\hline $\mathrm{BMI}\left(\mathrm{kg} / \mathrm{m}^{2}\right)$ & $31.08 \pm 3.52$ & $30.82 \pm 4.05$ & -0.26 & -0.61 & to & 0.05 & 0.094 \\
\hline Waist circumference (cm) & $104.75 \pm 9.76$ & $104.79 \pm 8.98$ & 0.04 & -1.34 & to & 1.52 & 0.896 \\
\hline Total Cholesterol (mg/dL) & $218.95 \pm 44.15$ & $208.51 \pm 41.26$ & -10.44 & -21.60 & to & 0.06 & 0.051 \\
\hline Tryglicerides (mg/dL) & $167.68 \pm 53.07$ & $151.02 \pm 83.70$ & -16.66 & -38.47 & to & 7.54 & 0.182 \\
\hline LDL cholesterol (mg/dL) & $140.25 \pm 39.67$ & $130.56 \pm 35.94$ & -9.69 & -19.85 & to & 0.04 & 0.051 \\
\hline HDL cholesterol (mg/dL) & $45.18 \pm 10.96$ & $47.38 \pm 11.42$ & 2.20 & 0.16 & to & 3.65 & 0.033 \\
\hline Serum glucose (mg/dL) & $92.57 \pm 11.78$ & $88.91 \pm 12.52$ & -3.66 & -7.02 & to & -0.47 & 0.026 \\
\hline $\mathrm{HbA} 1 \mathrm{c}$ & $5.59 \pm 0.66$ & $5.67 \pm 0.32$ & 0.08 & -0.11 & to & 0.30 & 0.367 \\
\hline Serum creatinine, $(\mathrm{mg} / \mathrm{dL})$ & $0.89 \pm 0.16$ & $0.90 \pm 0.19$ & 0.01 & -0.03 & to & 0.05 & 0.575 \\
\hline hs-c-reactive (mg/dL) & $0.26 \pm 0.21$ & $0.27 \pm 0.25$ & 0.01 & -0.04 & to & 0.05 & 0.687 \\
\hline Fibrinogen (mg/dL) & $327.05 \pm 59.07$ & $345.16 \pm 66.64$ & 18.11 & 6.87 & to & 44.21 & 0.009 \\
\hline HOMA-IR & $2.96 \pm 1.82$ & $2.22 \pm 1.33$ & -0.74 & -1.35 & to & -0.27 & 0.004 \\
\hline Office SBP (mm Hg) & $142.43 \pm 12.46$ & $134.95 \pm 15.52$ & -7.48 & -11.35 & to & -2.18 & 0.005 \\
\hline Office DBP (mm Hg) & $88.63 \pm 9.61$ & $84.92 \pm 10.26$ & -3.71 & -6.32 & to & -0.26 & 0.034 \\
\hline Office PP, mm Hg & $54.23 \pm 11.35$ & $50.77 \pm 12.78$ & -3.46 & -6.96 & to & 0.73 & 0.109 \\
\hline Office HR & $74.23 \pm 12.23$ & $72.44 \pm 11.66$ & -1.79 & -3.78 & to & 0.94 & 0.232 \\
\hline Mean Antihypertensive Drugs & $0.82 \pm 1.04$ & $1.34 \pm 1.20$ & 0.52 & 0.21 & to & 0.83 & 0.002 \\
\hline Antihypertensive Drugs, n (\%) & $21(47.70)$ & $31(72.10)$ & 24.40 & -44 & to & 40 & 0.001 \\
\hline Mean Lipid lowering drugs & $0.30 \pm 0.46$ & $0.43 \pm 0.55$ & 0.13 & 0.03 & to & 0.24 & 0.013 \\
\hline Lipid lowering drugs, n (\%) & $13(29.50)$ & $19(44.20)$ & 14.70 & -3.5 & to & 450.0 & 0.031 \\
\hline
\end{tabular}

Data for qualitative variables are expressed as $\mathrm{N}$ : number (\%) and quantitative variables as mean \pm standard deviation.

BMI: body mass index; LDL: low density lipoprotein; HDL: high density lipoprotein; HbA1C: glycosylated hemoglobin; HOMA-IR: homeostasis model assessment insulin resistance; SBP: Systolic blood pressure; DBP: Diastolic blood pressure; PP: pulse pressure; HR: heart rate.

lipid-lowering drugs between baseline and the evaluation after one year, a significant decrease was noted in BMI and diastolic blood pressure, together with an increase in fibrinogen and ABI in the patients with T2DM. In contrast, the patients with an initial diagnosis of Metabolic syndrome showed a significant drop in systolic and diastolic blood pressure, HOMA index and PWV, and an increase in HDL-Cholesterol, serum glucose, fibrinogen, ABI, Cornell voltage-duration product and antihypertensive and lipid-lowering drug use (Tables 1, 2, 3 and 4, Figure 1).

In the multiple regression analysis, the variables that remained in the equation explaining the changes in TOD parameters in patients with Metabolic syndrome were: the difference in antihypertensive drug use in PWV $\left(R^{2}=0.235\right)$, and the difference in antihypertensive and lipid-lowering drug use in relation to the Cornell voltage-duration product $\left(\mathrm{R}^{2}=0.258\right)$. However, in the diabetic patients and following the same regression analysis, the variable remaining in the model explaining the differences in PWV $\left(\mathrm{R}^{2}=0.133\right)$ and Cornell voltage-duration product $\left(\mathrm{R}^{2}=0.104\right)$ was seen to be the difference in systolic blood pressure (Table 5).

\section{Discussion}

The data obtained describe the evolution of to conventional and non-conventional risk factors and of las TOD vascular, cardiac and renal damage in patients with T2DM or metabolic syndrome over one year of followup. We observed a increase in ABI in the diabetics. In contrast, the patients with metabolic syndrome experienced an increase in ABI and Cornell voltage-duration product, and a decrease in PWV, probably as a result of an increased use of antihypertensive drugs.

The mean IMTCc in the patients with T2DM was $0.76 \mathrm{~mm}$, same in the two assessments. This being similar (taking age into account) to the data obtained in Caucasians with T2DM in the metaanalysis published by Brohall et al. [14]. The mean IMTCc in the two evaluations among the subjects with Metabolic syndrome was $0.75 \mathrm{~mm}$ and greater than the data of the Carmela study $(0.69 \mathrm{~mm})$. These differences are probably explained by 
Table 3 Target organ damage in Diabetics

\begin{tabular}{|c|c|c|c|c|c|c|c|}
\hline Variables & Basal evaluation & Annual review & Differences & IC 95\% & & p Value & \\
\hline \multicolumn{8}{|l|}{ Vascular } \\
\hline Carotid IMT men average (mm) & $0.76 \pm 0.12$ & $0.76 \pm 0.10$ & 0.00 & -1 & to & 1 & 0.82 \\
\hline Carotid IMT men average $\geq 90$ mm, n (\%) & $17(25.00)$ & $15(22.10)$ & -2.90 & -4.7 & to & 1.2 & 0.63 \\
\hline Carotid IMT maximum average (mm) & $0.94 \pm 0.14$ & $0.94 \pm 0.13$ & 0.00 & -0.01 & to & 0.01 & 0.74 \\
\hline Carotid IMT maximum average $\geq 90 \mathrm{~mm}, \mathrm{n}(\%)$ & $46(67.60)$ & $42(61.80)$ & -5.80 & -11 & to & 21 & 0.39 \\
\hline Plaques, n (\%) & $15(22.10)$ & $15(22.10)$ & 10 & -14 & to & 14 & 1.00 \\
\hline$A B \mid$ & $1.10 \pm 0.13$ & $1.17 \pm 0.08$ & 0.07 & 0.04 & to & 0.11 & $<0.001$ \\
\hline TOD ABI, n (\%) & $8(11.80)$ & $2(3.10)$ & -8.70 & -17 & to & 10 & 0.03 \\
\hline$P W,(m / s)$ & $9.59 \pm 2.32$ & $9.78 \pm 2.49$ & 0.19 & -0.26 & to & 0.77 & 0.33 \\
\hline $\mathrm{PWV} \geq 12 \mathrm{~m} / \mathrm{s}, \mathrm{n}(\%)$ & $10(15.20)$ & $11(17.50)$ & 2 & -10 & to & 14 & 0.63 \\
\hline TOD Vascular, n (\%) & $25(37.90)$ & $23(36.50)$ & -14 & -18 & to & -10 & 0.75 \\
\hline \multicolumn{8}{|l|}{ Renal } \\
\hline GFR CKD-EPI (mL/min/1.73 m2) & $87.95 \pm 13.06$ & $88.64 \pm 15.35$ & 0.69 & -2.09 & to & 3.32 & 0.65 \\
\hline TOD GFR CKD-EPI $\leq 60 \mathrm{~mL} / \mathrm{min} / 1.73 \mathrm{m2}, \mathrm{n}(/ \%)$ & $1(1.50)$ & $3(4.70)$ & 3 & -3 & to & 15 & 0.50 \\
\hline Albumin/creatinine (mg/g) & $36.09 \pm 82.81$ & $34.88 \pm 75.98$ & -1.21 & -20.80 & to & 15.05 & 0.75 \\
\hline TOD Albumin/creatinine (mg/g), n (\%) & $11(16.20)$ & $9(14.50)$ & -1.70 & -15 & to & 9 & 0.06 \\
\hline TOD Renal n (\%) & $13(20.00)$ & $12(19.40)$ & -0.60 & -0.74 & to & -0.50 & 0.63 \\
\hline \multicolumn{8}{|l|}{ Heart } \\
\hline Cornell VDP (mmms) & $1648.29 \pm 654.68$ & $1584.79 \pm 522.69$ & -29.91 & -118.71 & to & 58.88 & 0.50 \\
\hline TOD Cornell VDP (mmms) patologico, n(\%) & $7(10.30)$ & $5(7.80)$ & -2.50 & -12 & to & 7 & 0.25 \\
\hline TOD global, n (\%) & $34(51.50)$ & $32(50.80)$ & -0.7 & -1.9 & to & 1.5 & 0.75 \\
\hline
\end{tabular}

Data for qualitative variables are expressed as $\mathrm{N}^{\circ}(\%)$ and quantitative variables as mean \pm standard deviation.

IMT: Intima-media thickness; ABI: ankle-brachial index; TOD: Target organ damage: PWV: Pulse wave velocity; GFR: glomerular filtration rate; CKD-EPI: Chronic Kidney Disease Epidemiology Collaboration; PDV: Voltage-duration product

Table 4 Target Organ damage in Metabolic Syndrome

\begin{tabular}{|c|c|c|c|c|c|c|c|}
\hline Variables & Basal evaluation & Annual review & Differences & IC 95\% & & p Value & \\
\hline \multicolumn{8}{|l|}{ Vascular } \\
\hline Carotid IMT men average (mm) & $0.75 \pm 0.12$ & $0.76 \pm 0.12$ & 0.00 & -0.01 & to & 0.02 & 0.40 \\
\hline Carotid IMT men average $\geq 90$ mm, n (\%) & $6(13.60)$ & $5(11.40)$ & -2.20 & -16 & to & 11 & 0.62 \\
\hline Carotid IMT maximum average $(\mathrm{mm})$ & $0.93 \pm 0.15$ & $0.93 \pm 0.15$ & 0.00 & -0.02 & to & 0.03 & 0.63 \\
\hline Carotid IMT maximum average $\geq 90$ mm, n (\%) & $25(56.80)$ & $23(52.30)$ & -4.50 & -24 & to & 18 & 0.39 \\
\hline Plaques, n (\%) & $3(6.80)$ & $3(6.90)$ & 0.1 & -10 & to & 11 & 1.00 \\
\hline$A B \mid$ & $1.10 \pm 0.10$ & $1.15 \pm 0.09$ & 0.05 & 0.01 & to & 0.09 & 0.03 \\
\hline TOD ABI, n (\%) & $1(2.30)$ & $2(4.70)$ & 2.40 & -5 & to & 10 & 0.03 \\
\hline $\mathrm{PW},(\mathrm{m} / \mathrm{s})$ & $9.34 \pm 2.69$ & $8.57 \pm 2.22$ & -0.77 & -1.50 & to & 0.07 & 0.04 \\
\hline $\mathrm{PW} \geq 12 \mathrm{~m} / \mathrm{s}, \mathrm{n}(\%)$ & $7(15.90)$ & $2(4.70)$ & -11.20 & -24 & to & 12 & 0.75 \\
\hline TOD Vascular, n (\%) & $11(25.00)$ & $6(14.00)$ & -11 & -27 & to & 54 & 0.06 \\
\hline \multicolumn{8}{|l|}{ Renal } \\
\hline GFR CKD-EPI (mL/min/1.73 m2) & $88.57 \pm 13.89$ & $87.26 \pm 16.03$ & -1.31 & -5.15 & to & 2.58 & 0.50 \\
\hline TOD GFR CKD-EPI $\leq 60 \mathrm{~mL} / \mathrm{min} / 1.73 \mathrm{~m} 2, \mathrm{n}(/ \%)$ & $0(0.00)$ & $3(7.00)$ & 7 & -1 & to & 15 & 0.25 \\
\hline Albumin/creatinine (mg/g) & $17.31 \pm 39.04$ & $28.89 \pm 133.82$ & 11.58 & -30.36 & to & 55.92 & 0.55 \\
\hline TOD Albumin/creatinine (mg/g), n (\%) & $7(16.30)$ & $1(2.40)$ & 13.90 & -25 & to & -2 & 0.06 \\
\hline TOD Renal n (\%) & $7(16.30)$ & $5(11.90)$ & -4.40 & -18 & to & 10 & 1.00 \\
\hline \multicolumn{8}{|l|}{ Heart } \\
\hline Cornell VDP (mmms) & $1486.64 \pm 457.67$ & $1661.89 \pm 536.983$ & 184.22 & 62.28 & to & 306.15 & 0.01 \\
\hline TOD Cornell VDP (mmms) patologico, n(\%) & $1(2.30)$ & $4(9.30)$ & 7 & -3 & to & 17 & 0.25 \\
\hline TOD global, n (\%) & $1(2.30)$ & $4(9.30)$ & 7 & -3 & to & 17 & 0.25 \\
\hline
\end{tabular}

Data for qualitative variables are expressed as $\mathrm{N}^{\circ}(\%)$ and quantitative variables as mean \pm standard deviation.

IMT: Intima-media thickness; ABI: ankle-brachial index; TOD: Target organ damage: PWV: Pulse wave velocity; GFR: glomerular filtration rate; CKD-EPI: Chronic Kidney Disease Epidemiology Collaboration; PDV: Voltage-duration product 


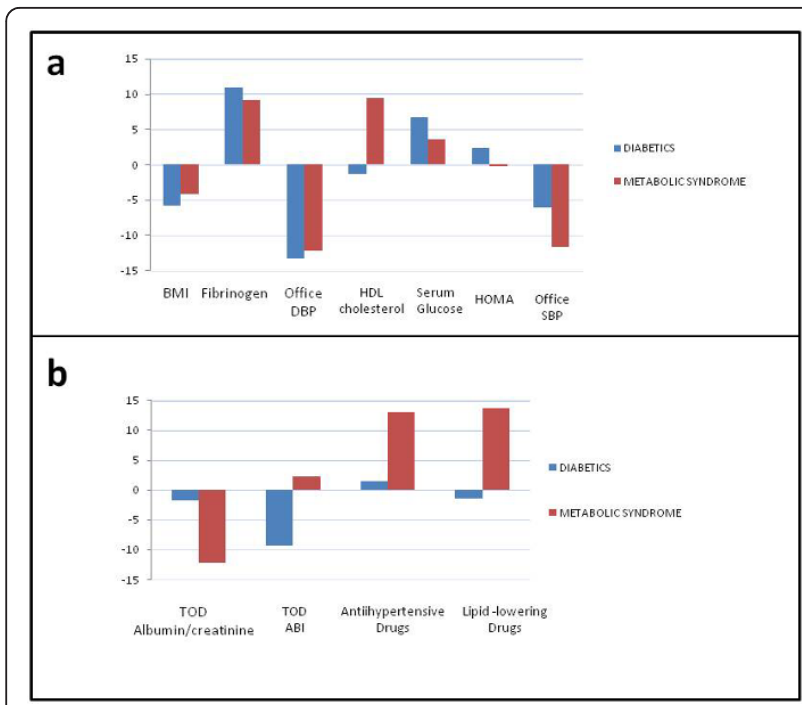

Figure 1 Changes between baseline and evaluation after one year of follow-up. Changes between baseline and evaluation after one year of follow-up in target organ damage (a) and other study variables (b) in subjects with T2DM or Metabolic syndrome, adjusting the values of the differences to a scale of -100 to 100 . IMT: intima-media thickness; ABI: ankle/brachial index; PWV: pulse wave velocity; VDP: voltage-duration product; BMI: body mass index; SBP: systolic blood pressure; DBP: diastolic blood pressure. patient age, since in this study the subjects with Metabolic syndrome were comparatively younger [29].

The mean PWV values in the diabetics $(9.59 \mathrm{~m} / \mathrm{sec}$ at initial measurement and $9.78 \mathrm{~m} / \mathrm{sec}$ after one year of follow-up) were similar to those reported by Lacy et al. [30], and higher than those recorded in population-based studies [16,31]. In the patients with metabolic syndrome, the mean PWV decreased from 9.34 to $8.57 \mathrm{~m} / \mathrm{sec}$, a situation explained by the increased use of antihypertensive treatment (from 0.82 to 1.34 drugs per patient), which is presently the most potent option for reducing arterial stiffness [32]. Likewise, antihypertensive drug use is the variable explaining the variability in the differences in the regression analysis.

The behavior of ABI was similar in both patient groups, with an increase after one year of follow-up. Similar data have been published by Ito et al. [33] in patients with T2DM. However, it must be remembered that in diabetic patients the standard threshold sensitivity (0.9) is lower as a result of which the efficiency of $\mathrm{ABI}$ is limited. Moreover, in this group of patients the sensitivity for values between 0.9-1.3 is low (15-79\%) $[34,35]$. In the improved results of $\mathrm{ABI}$, one of the

Table 5 Factors influencing the differences between the two evaluations of target organ damage in diabetics and patients with metabolic syndrome, in the multiple regression analysis

\begin{tabular}{|c|c|c|c|c|c|c|c|}
\hline Diabetics & Metabolic syndrome & & & & & & \\
\hline & $\beta$ & IC $95 \%$ & $\mathrm{p}$ & & $\beta$ & IC 95\% & p Value \\
\hline D-IMT Adjusted R2 = 0.001 & & D-IMT Adjusted R2 = 0.038 & & & & & \\
\hline Constant & -0.01 & -0.09 to 0.09 & 0.97 & constant & 0.04 & 0.06 to 0.14 & 0.40 \\
\hline Age & -0.01 & -0.01 to 0.01 & 0.43 & Age & -0.01 & 0.01 to 0.01 & 0.14 \\
\hline Gender & 0.02 & -0.01 to 0.05 & 0.21 & Gender & 0.02 & 0.02 to 0.06 & 0.32 \\
\hline D-PWV Adjusted $\mathrm{R}^{2}=0.133$ & & D-PWV Adjusted $\mathrm{R}^{2}=0.235$ & & & & & \\
\hline Constant & -1.97 & -6.87 to 2.93 & 0.42 & constant & 2.57 & 1.34 to 6.48 & 0.19 \\
\hline Age & 0.04 & -0.04 to 0.12 & 0.28 & Age & -0.05 & 0.12 to 0.01 & 0.09 \\
\hline Gender & 0.22 & -1.07 to 1.51 & 0.73 & Gender & 1.13 & 0.59 to 2.86 & 0.19 \\
\hline D-DBP & 0.05 & 0.01 to 0.08 & 0.01 & D-FHTA & -1.44 & 2.39 to -0.50 & 0.01 \\
\hline $\begin{array}{l}\text { D-PDV DE CORNELL } \\
\text { Adjusted } R^{2}=0.104\end{array}$ & & $\begin{array}{l}\text { D-PDV DE CORNELL } \\
\text { Adjusted } R^{2}=0.258\end{array}$ & & & & & \\
\hline Constant & 124.16 & -889.48 to 1137.79 & 0.80 & constant & -74.32 & -600.14 to 451.49 & 0.77 \\
\hline Age & -2.57 & -18.74 to 13.59 & 0.75 & Age & 4.63 & 4.15 to 13.421 & 0.29 \\
\hline Gender & -18.44 & -248.79 to 285.66 & 0.89 & Gender & -19.19 & 251.72 to 213.33 & 0.87 \\
\hline D-DBP & 7.89 & 0.88 to 14.90 & 0.03 & D-FHTA & -440.80 & 139.92 to 741.69 & 0.01 \\
\hline D-ABI Adjusted $\mathrm{R}^{2}=0.036$ & & $\underline{\mathrm{D}-\mathrm{ABI}}$ Adjusted $\mathrm{R}^{2}=0.005$ & & & & & \\
\hline Constant & -0.095 & -0.25 to 0.06 & 0.22 & constant & -0.06 & 0.25 to 0.12 & 0.51 \\
\hline Age & 0.02 & 0.01 to 0.04 & 0.12 & Age & 0.01 & 0.01 to 0.01 & 0.36 \\
\hline Gender & 0.04 & -0.01 to 0.10 & 0.14 & Gender & 0.01 & 0.03 to 0.03 & 0.23 \\
\hline
\end{tabular}

Dependent variable: D-IMT: difference Intima-media thickness; D-PWV: difference pulse wave velocity; D-PDV DE CORNELL: difference voltage-duration product CORNELL. D-ABI: difference ankle-brachial index

Adjustment variables:Age; Gender: (male $=1$; female $=0$ ).

Independent variables: D-BMI: difference body mass index; D-Fibrinogen: difference fibrinogen; D-HDL: difference high density lipoprotein; D-serum glucose: difference serum glucose; D-HOMA-IR: difference homeostasis model assessment insulin resistance; D-SBP: difference sistolic blood pressure; D-DBP: difference diastolic blood pressure. D-FHTA: D-Antihypertensive Drugs; D-FHPL: D-Hypolipidemic drugs.

R2: determination coefficient; $p$ : statistically significant differences $(p<0.05)$. 
possible causes for the increase in the first year is the decrease in brachial systolic pressure, without an accompanying decrease at pedal or tibial artery due to the atherosclerosis of these patients, in addition to the between- and within-observer variability there may be between the two measurements.

The evaluation of left ventricular hypertrophy based on the Cornell voltage-duration product did not vary between the two evaluation time points in the diabetic patients, though it was seen to increase at the second measurement in the patients with metabolic syndrome. Apart from the low sensitivity (31\%) of electrocardiography in detecting left ventricular hypertrophy, the electrocardiographic criteria are of little diagnostic use in the isolated interpretation of a patient with left ventricular hypertrophy [8]. In any case, the ELECTROPRES platform, implemented in several Spanish centers, has concluded that the criteria of the Lewis index (R-I+ SIII) and Cornell product ([R-aVL $+\mathrm{S}-\mathrm{V} 3][+6$ in women]) [36]were those which detected most cases of left ventricular hypertrophy.

There were no differences in glomerular filtration rate estimated with the CKD-EPI equation either between evaluation timepoints or between groups the values in all cases being over $85 \mathrm{ml} / \mathrm{min} / 1.73 \mathrm{~m}^{2}$ and greater than those recorded in other studies [33,37]. Likewise, we observed no differences between the two evaluations in terms of the albumin-creatine index the values being lower in the subjects with Metabolic syndrome, and also lower than the values published for diabetic subjects in our setting [37].

This study has some limitations that must be considered when interpreting the results obtained. Firstly, the number of subjects per group, which limits the power of an analyses made, as well as follow-up limited to the first year of the study. It also should be taken into account that selection was not randomized but involved consecutive sampling, and the two groups are not fully balanced in terms of age (4 years of difference) - a fact that may influence the course, though the analyses have been adjusted for this variable in order to minimize its influence.

The annual assessment of cardiovascular risk factors and the decrease in pulse wave velocity was more favorable in the patients with metabolic syndrome, probably influenced by the increased percentage of subjects treated with antihypertensive and lipid lowering drugs in this group.

\section{Abbreviations}

T2DM: Diabetes mellitus tipo 2; TOD: target organ damage; LVH: Left ventricular hypertrophy; IMT: Intima-media thickness; PWV: Pulse wave velocity; IMTCc: Intima-media thickness of the common carotid artery; ABI: Ankle-brachial index; PWV: Pulse wave velocity; SBP:Systolic blood pressure:
DBP: Dyastolic blood pressure; PP: Pulse pressure; GFR: glomerular filtration rate; CKD-EPI: Chronic Kidney Disease Epidemiology Collaboration.

\section{Acknowledgements}

This project was supported by the Regional Health Management of Castilla y León (SACYL) in the call on March 262009 and resolved on July 72009 (GRS. 428/A/09), ISCIII (RD06/018/27) and FEDER funds.

\section{Author details}

'Primary Care Research Unit, La Alamedilla Health Centre, Salamanca, Spain. ${ }^{2}$ Statistics Department, University of Salamanca, Salamanca, Spain

\section{Authors' contributions}

MAGM devised the study, designed the protocol, participated in fund raising, interpretation of results, prepared the manuscript draft and corrected the final version of the manuscript. JIRR and CAC participated in the study design, data collection and manuscript review. MCPA performed all analytical methods, interpretation of results, and manuscript review. ERS, LGS and LGS participated in the study design, interpretation of results, and manuscript review. LGO participated in the protocol design, fund raising, analysis of results, and final review of the manuscript. Finally, all authors reviewed and approved the final version of the manuscript.

\section{Competing interests}

The authors declare that they have no competing interests.

Received: 7 September 2011 Accepted: 14 October 2011 Published: 14 October 2011

\section{References}

1. Barnett KN, Ogston SA, McMurdo ME, Morris AD, Evans JM: A 12-year follow-up study of all-cause and cardiovascular mortality among 10,532 people newly diagnosed with Type 2 diabetes in Tayside, Scotland. Diabet Med 2010, 27(10):1124-1129.

2. Kondo T, Osugi S, Shimokata K, Honjo H, Morita Y, Yamashita K, Maeda K, Muramatsu T, Shintani S, Matsushita K, Murohara T: Metabolic syndrome and all-cause mortality, cardiac events, and cardiovascular events: a follow-up study in 25,471 young- and middle-aged Japanese men. Eur J Cardiovasc Prev Rehabil 2011.

3. Sidorenkov O, Nilssen O, Grjibovski AM: Metabolic syndrome in Russian adults: associated factors and mortality from cardiovascular diseases and all causes. BMC Public Health 2010, 10:582.

4. Wannamethee SG, Shaper AG, Whincup PH, Lennon L, Sattar N: Impact of diabetes on cardiovascular disease risk and all-cause mortality in older men: influence of age at onset, diabetes duration, and established and novel risk factors. Arch Intern Med 2011, 171(5):404-410.

5. Sehestedt T, Olsen MH: Subclinical organ damage and cardiovascular risk prediction. Blood Press 2010, 19(3):132-139.

6. Xu L, Jiang CQ, Lam TH, Lin JM, Yue XJ, Cheng KK, Liu B, Jin YL, Zhang WS, Thomas GN: The metabolic syndrome is associated with subclinical atherosclerosis independent of insulin resistance: the Guangzhou Biobank Cohort Study-CVD. Clin Endocrinol (Oxf) 2010, 73(2):181-188.

7. Somaratne JB, Whalley GA, Poppe KK, Ter Bals MM, Wadams G, Pearl A, Bagg W, Doughty RN: Screening for left ventricular hypertrophy in patients with type 2 diabetes mellitus in the community. Cardiovasc Diabetol 2011, 10(1):29

8. Havranek EP, Froshaug DB, Emserman CD, Hanratty R, Krantz MJ, Masoudi FA, Dickinson LM, Steiner JF: Left ventricular hypertrophy and cardiovascular mortality by race and ethnicity. Am J Med 2008, 121(10):870-875.

9. Anavekar NS, McMurray JJ, Velazquez EJ, Solomon SD, Kober L, Rouleau JL, White HD, Nordlander R, Maggioni A, Dickstein K, Zelenkofske S, Leimberger JD, Califf RM, Pfeffer MA: Relation between renal dysfunction and cardiovascular outcomes after myocardial infarction. N Engl J Med 2004, 351(13):1285-1295

10. Gerstein HC, Mann JF, Yi Q, Zinman B, Dinneen SF, Hoogwerf B, Halle JP, Young J, Rashkow A, Joyce C, Nawaz S, Yusuf S: Albuminuria and risk of cardiovascular events, death, and heart failure in diabetic and nondiabetic individuals. Jama 2001, 286(4):421-426.

11. Fowkes FG, Murray GD, Butcher I, Heald CL, Lee RJ, Chambless LE, Folsom AR, Hirsch AT, Dramaix M, deBacker G, Wautrecht JC, Kornitzer M, 
Newman AB, Cushman M, Sutton-Tyrrell K, Lee AJ, Price JF, d'Agostino RB, Murabito JM, Norman PE, Jamrozik K, Curb JD, Masaki KH, Rodriguez BL, Dekker JM, Bouter LM, Heine RJ, Nijpels G, Stehouwer CD, Ferrucci L, et al: Ankle brachial index combined with Framingham Risk Score to predict cardiovascular events and mortality: a meta-analysis. Jama 2008, 300(2):197-208.

12. Einarson TR, Hunchuck J, Hemels M: Relationship between blood glucose and carotid intima media thickness: A meta-analysis. Cardiovasc Diabetol 2010, 9:37.

13. Faeh D, William J, Yerly P, Paccaud F, Bovet P: Diabetes and pre-diabetes are associated with cardiovascular risk factors and carotid/femoral intima-media thickness independently of markers of insulin resistance and adiposity. Cardiovasc Diabetol 2007, 6:32.

14. Brohall G, Oden A, Fagerberg B: Carotid artery intima-media thickness in patients with Type 2 diabetes mellitus and impaired glucose tolerance: a systematic review. Diabet Med 2006, 23(6):609-616.

15. Vlachopoulos C, Aznaouridis K, Stefanadis C: Prediction of cardiovascular events and all-cause mortality with arterial stiffness: a systematic review and meta-analysis. J Am Coll Cardiol 2010, 55(13):1318-1327.

16. Mitchell GF, Hwang SJ, Vasan RS, Larson MG, Pencina MJ, Hamburg NM, Vita JA, Levy D, Benjamin EJ: Arterial stiffness and cardiovascular events: the Framingham Heart Study. Circulation 2010, 121(4):505-511.

17. Kim YJ, Cho BM, Lee S: Metabolic syndrome and arterial pulse wave velocity. Acta Cardiol 2010, 65(3):315-321.

18. Tentolouris N, Papazafiropoulou A, Moyssakis I, Liatis S, Perrea D, Kostakis M, Katsilambros N: Metabolic syndrome is not associated with reduction in aortic distensibility in subjects with type 2 diabetes mellitus. Cardiovasc Diabetol 2008, 7:1.

19. Nomura K, Hamamoto Y, Takahara S, Kikuchi O, Honjo S, Ikeda H, Wada Y, Nabe K, Okumra R, Koshiyama H: Relationship between carotid intimamedia thickness and silent cerebral infarction in Japanese subjects with type 2 diabetes. Diabetes Care 2010, 33(1):168-170.

20. Diagnosis and classification of diabetes mellitus. Diabetes Care 2010, 33(Suppl 1):S62-69.

21. Grundy SM, Cleeman JI, Daniels SR, Donato KA, Eckel RH, Franklin BA, Gordon DJ, Krauss RM, Savage PJ, Smith SC Jr, Spertus JA, Costa F: Diagnosis and management of the metabolic syndrome: an American Heart Association/National Heart, Lung, and Blood Institute Scientific Statement. Circulation 2005, 112(17):2735-2752.

22. World Medical Association declaration of Helsinki. Recommendations guiding physicians in biomedical research involving human subjects. Jama 1997, 277(11):925-926.

23. Gomez-Marcos MA, Recio-Rodriguez Jl, Rodriguez-Sanchez E, CastanoSanchez Y, de Cabo-Laso A, Sanchez-Salgado B, Rodriguez-Martin C, Castano-Sanchez C, Gomez-Sanchez L, Garcia-Ortiz L: Central blood pressure and pulse wave velocity: relationship to target organ damage and cardiovascular morbidity-mortality in diabetic patients or metabolic syndrome. An observational prospective study. LOD-DIABETES study protocol. BMC Public Health 2010, 10:143.

24. Mancia G, De Backer G, Dominiczak A, Cifkova R, Fagard R, Germano G, Grassi G, Heagerty AM, Kjeldsen SE, Laurent S, Narkiewicz K, Ruilope L, Rynkiewicz A, Schmieder RE, Boudier HA, Zanchetti A, Vahanian A, Camm J, De Caterina R, Dean V, Dickstein K, Filippatos G, Funck-Brentano C, Hellemans I, Kristensen SD, McGregor K, Sechtem U, Silber S, Tendera M, Widimsky P, et al: 2007 Guidelines for the Management of Arterial Hypertension: The Task Force for the Management of Arterial Hypertension of the European Society of Hypertension (ESH) and of the European Society of Cardiology (ESC). J Hypertens 2007, 25(6):1105-1187.

25. Touboul PJ, Hennerici MG, Meairs S, Adams H, Amarenco P, Bornstein N, Csiba L, Desvarieux M, Ebrahim S, Fatar M, Hernandez Hernandez R, Jaff M, Kownator S, Prati P, Rundek T, Sitzer M, Schminke U, Tardif JC, Taylor A, Vicaut E, Woo KS, Zannad F, Zureik M: Mannheim carotid intima-media thickness consensus (2004-2006). An update on behalf of the Advisory Board of the 3rd and 4th Watching the Risk Symposium, 13th and 15th European Stroke Conferences, Mannheim, Germany, 2004, and Brussels, Belgium, 2006. Cerebrovasc Dis 2007, 23(1):75-80.

26. Levey AS, Stevens LA, Schmid CH, Zhang YL, Castro AF, Feldman HI, Kusek JW, Eggers P, Van Lente F, Greene T, Coresh J, Ckd EPI: A new equation to estimate glomerular filtration rate. Ann Intern Med 2009, 150(9):604-612.
27. Okin PM, Roman MJ, Devereux RB, Kligfield P: Electrocardiographic identification of increased left ventricular mass by simple voltageduration products. J Am Coll Cardiol 1995, 25(2):417-423.

28. Martin-Moreno JM, Boyle P, Gorgojo L, Maisonneuve P, FernandezRodriguez JC, Salvini S, Willett WC: Development and validation of a food frequency questionnaire in Spain. Int J Epidemiol 1993, 22(3):512-519.

29. Escobedo J, Schargrodsky H, Champagne B, Silva H, Boissonnet CP, Vinueza R, Torres M, Hernandez R, Wilson E: Prevalence of the metabolic syndrome in Latin America and its association with sub-clinical carotid atherosclerosis: the CARMELA cross sectional study. Cardiovasc Diabetol 2009, 8:52.

30. Lacy PS, O'Brien DG, Stanley AG, Dewar MM, Swales PP, Williams B: Increased pulse wave velocity is not associated with elevated augmentation index in patients with diabetes. J Hypertens 2004, 22(10):1937-1944.

31. Determinants of pulse wave velocity in healthy people and in the presence of cardiovascular risk factors: 'establishing normal and reference values'. Eur Heart J 2010, 31(19):2338-2350.

32. Stehouwer $C D$, Henry RM, Ferreira I: Arterial stiffness in diabetes and the metabolic syndrome: a pathway to cardiovascular disease. Diabetologia 2008, 51(4):527-539.

33. Ito H, Komatsu Y, Mifune M, Antoku S, Ishida H, Takeuchi Y, Togane M: The estimated GFR, but not the stage of diabetic nephropathy graded by the urinary albumin excretion, is associated with the carotid intimamedia thickness in patients with type 2 diabetes mellitus: a crosssectional study. Cardiovasc Diabetol 2010, 9:18.

34. Dachun X, Jue L, Liling Z, Yawei X, Dayi H, Pagoto SL, Yunsheng M: Sensitivity and specificity of the ankle-brachial index to diagnose peripheral artery disease: a structured review. Vasc Med 2010, 15(5):361-369

35. Potier L, Abi Khalil C, Mohammedi K, Roussel R: Use and utility of ankle brachial index in patients with diabetes. Eur I Vasc Endovasc Surg 2011, 41(1):110-116.

36. Barrios V, Calderon A, Coca A, Gonzalez-Juanatey JR, Sarria A, RodriguezPadial L: Computerized interpretation of the electrocardiogram in the diagnosis of left ventricular hypertrophy. The ELECTROPRES project. Rev Clin Esp 2011, 211(8):391-399.

37. Rodriguez-Poncelas A, Quesada Sabate M, Coll De Tuero G, Caula Ros J, Gelada-Batlle E, Gomez-Marcos MA, Garre-Olmo J, Garcia-Ortiz L, Comalada Daniel C, Ramos Blanes R: Prevalence of occult chronic kidney disease and associated variables in a population of patients with type 2 diabetes. Med Clin (Barc) 2010, 134(6):239-245.

doi:10.1186/1475-2840-10-90

Cite this article as: Gomez-Marcos et al:: Yearly evolution of organ damage markers in diabetes or metabolic syndrome: data from the LOD-DIABETES study. Cardiovascular Diabetology 2011 10:90.

\section{Submit your next manuscript to BioMed Central and take full advantage of:}

- Convenient online submission

- Thorough peer review

- No space constraints or color figure charges

- Immediate publication on acceptance

- Inclusion in PubMed, CAS, Scopus and Google Scholar

- Research which is freely available for redistribution

Submit your manuscript at www.biomedcentral.com/submit 